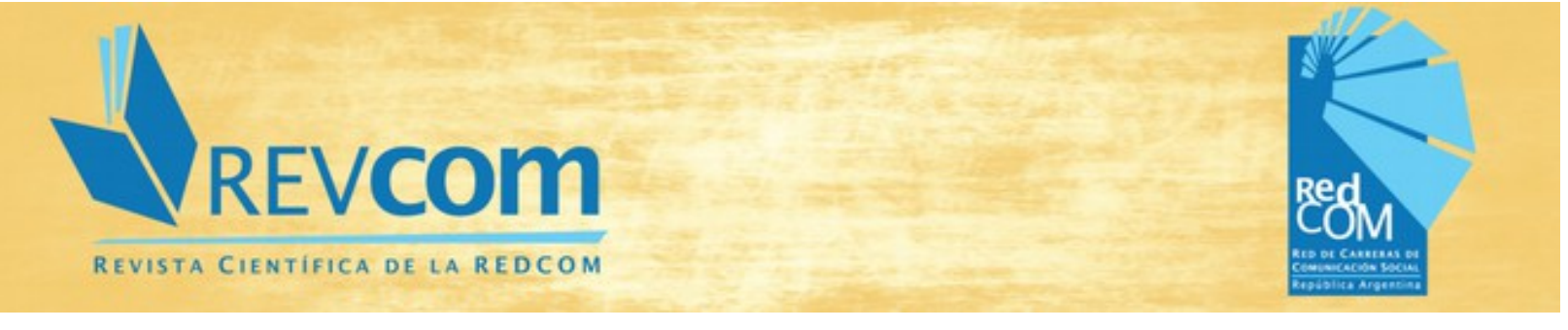

REVCOM | ISSN 2451-7836 | Año 4, \#8 | mayo de 2019 | Contribuciones | e009

\title{
Una redefinición de la información
}

\author{
Sebastián Ernesto Ackerman \\ UNIVERSIDAD DE BUENOS AIRES \\ sebasackerman@gmail.com
}

\begin{abstract}
Resumen
A partir de la discusión por las retenciones móviles en 2008, el campo periodístico se dividió entre "Periodismo independiente" vs "Periodismo militante" como dos formas de ejercer la profesión. Por supuesto, esta dicotomía se planteó desde el sentido común dominante, que definía al periodismo como un "reflejo" de la realidad, por lo que la (supuesta) independencia era un atributo irrenunciable. Pero nosotros tomamos ese debate para intentar un nuevo acercamiento al estudio del periodismo gráfico. Lo que proponemos en este artículo es la redefinición de un concepto clave para estas investigaciones, como es el de información, como una forma particular de producción social de significaciones que borra sus propias huellas de producción. De esta manera, se abre un nuevo terreno para explorar las condiciones a partir de las cuales el sentido común se consolida en una sociedad.
\end{abstract}

Palabras clave: periodismo; información; sentido común; ideología

\section{Resumo}

No contexto da discussão sobre um imposto diferenciado ao setor agro-exportador em 2008, o campo jornalístico dividiu-se entre "jornalismo independente" e "jornalismo militante" como duas formas de praticar a profissão. Logicamente, essa dicotomia foi levantada a partir do senso comum dominante, que definiu o jornalismo como uma "reflexão" da realidade, de modo que a (suposta) independência era um atributo irrevogável.

No entanto, nós focamos aqui nesse debate para tentar uma nova abordagem sobre o estudo do jornalismo gráfico. Propomos neste artigo a redefinição de um conceitochave para essas pesquisas: a informação, como uma forma particular de produção social de significados que apaga seus próprios traços de produção. Desta forma, abrese um novo plano para explorar as condições a partir das quais o senso comum é consolidado em uma sociedade.

Palavras-chave: Jornalismo - Informação - Senso comum - Ideologia 
REVCOM | ISSN 2451-7836 | Año 4, \#8 | mayo de 2019 | Contribuciones | e009

En los últimos años, la cuestión del vínculo entre la práctica periodística, su producto (la noticia, como elemento basal de un conjunto de subproductos que podríamos denominar "derivados" como la crónica, la opinión, la entrevista, etcétera) y lo que por ahora llamaremos la realidad estuvo en el centro de una serie de debates que desestabilizaron el sentido común acerca de los medios de comunicación en general, y de la prensa gráfica en particular. Nos referimos a la idea de los medios como un "reflejo", un "puente" o una "ventana" de la realidad, en la que su mostración no afecta en nada aquello que se refleja, a lo que permite el acceso o lo que se observa a través de ellos.

Sin embargo, esta idea (que a nuestro criterio al menos en Argentina comenzó a construirse en el primer tercio del siglo XX y de allí logró consolidarse) fue resquebrajándose desde principios del siglo XXI, y encontró un gran mojón en el debate que en 2008 se dio en torno a la Resolución 125, que proponía retenciones móviles a las exportaciones agropecuarias. ¿Por qué? Porque fue en aquel contexto que comenzó a hablarse de "Periodismo independiente vs. Periodismo militante" señalando una (supuesta) diferencia entre un periodismo sin intereses, que "refleja" la realidad, y otro que sí tenía intereses y que entonces era "tendencioso". Y la necesidad de reforzar explícitamente esta idea, de manifestar la (supuesta) diferencia entre estas dos posturas enunciativas consideramos que se produce porque el sentido común construido sobre el periodismo dejó de funcionar implícitamente, como lo venía haciendo hasta ese momento.

Pero también creemos que este proceso continúa, más cercano en el tiempo, en la definición teórica de lo que se conoce como "pos verdad", que en términos generales sostiene que las noticias son la constitución de verosímiles que apuntan a la construcción de una realidad tamizada por una dimensión afectiva, dotando de sentido una configuración factual que podría tener otras tantas. En otras palabras, la presentación de un sentido de la realidad para legitimarla socialmente al multiplicar esa representación. Así, los hechos objetivos tienen menos peso que el investimento afectivo con que los sujetos "interpretan" la realidad. Y así la dotan de sentido: justo/injusto, honesto/corrupto, libertad/represión, etcétera.

Hace algunos años a esto se lo llamaba "operación mediática" o "pescado podrido". No es tema para este artículo, pero en estos casos podía exculparse al periodista ( $\mathrm{y}$ al medio en el que trabaja) de la intencionalidad de difundir una falsedad. En el caso de la pos verdad esa exoneración resulta imposible: esta nueva etapa en el debate "Periodismo independiente vs. 


\section{REVCOM \\ REVISTA CIENTIFICA DE LA REDCOM}

REVCOM | ISSN 2451-7836 | Año 4, \#8 | mayo de 2019 | Contribuciones | e009

Periodismo militante" es una consecuencia de la disputa por la representación de la realidad a través de una forma de organizarla y hacerla inteligible, y que a través de la definición teórica de la "pos verdad" intenta darle un halo de legitimidad y difuminar la manipulación mediática.

Sin embargo, esta disputa no es nueva: para nosotros, es constitutiva del campo periodístico nacional desde sus orígenes. Recordemos que incluso La gazeta de Buenos Ayres (periódico cuya primera aparición fue el 7 de junio de 1810, por lo que hoy se celebra el Día del periodista en esa fecha) surgió para legitimar al proceso revolucionario independentista en estas tierras.

Nuestra propuesta, entonces, girará en torno a la redefinición de un concepto central para el periodismo: la "información". Creemos que este es un movimiento necesario para iluminar con nuevas reflexiones a las teorías sobre el periodismo. Para llegar a materializarla, deberemos realizar un rodeo conceptual: visitaremos las definiciones de sentido, su relación con las significaciones sociales y desde allí la posibilidad de la nueva conceptualización de la "información". Las propuestas aquí desarrolladas fueron el puntapié inicial de otro trabajo", y tanto en aquél como en estas líneas sabemos que existen otros caminos para pensar la práctica periodística y la información relacionados con el desarrollo de las nuevas tecnologías de la comunicación, sobre todo las redes sociales, pero nuestra intervención corre por carriles teóricos y epistemológicos diferentes, que no podemos desarrollar aquí.

\section{La problemática del sentido}

Puede resultar útil para el análisis los planteos de Eliseo Verón a propósito de lo que él denomina la semiosis social, entendiéndola como una red infinita interdiscursiva, ${ }^{2}$ por lo que el elemento que se constituye como "objeto de análisis" no es una propiedad del "texto" en sí, ni algo radicalmente externo a él. Son, más bien, los

sistemas de relaciones: sistemas de relaciones que todo producto significante mantiene con sus condiciones de generación, por una parte, y con sus efectos por la otra. (...) En el marco de una teoría de la semiosis social, la distinción es puramente metodológica; se produce automáticamente a partir del momento en que elegimos un conjunto discursivo para analizar (Verón, 1998: 128, 129).

1 Las reflexiones de este texto tienen una amplitud y un desarrollo mayor en la tesis de Maestría en Periodismo de la Facultad de Ciencias Sociales (UBA) Las condiciones de posibilidad del surgimiento de Página/12.

2 Para mayor profundización en los conceptos propuestos por este autor, véase Verón, Eliseo, La semiosis social, ed. Gedisa, 1998. 
REVCOM | ISSN 2451-7836 | Año 4, \#8 | mayo de 2019 | Contribuciones | e009

Así, la teoría de los discursos sociales en tanto modos de funcionamiento de la semiosis social, la dimensión significante de los fenómenos sociales, es el estudio de estos fenómenos en tanto procesos de producción de sentido, y reposa sobre una doble hipótesis:

- Toda producción de sentido es necesariamente social: no se puede describir ni explicar satisfactoriamente un proceso significante, sin explicar sus condiciones sociales productivas.

- Todo fenómeno social es, en una de sus dimensiones constitutivas, un proceso de producción de sentido, cualquiera que fuere el nivel de análisis. (Verón; 1998, 125).

Esta producción de sentido tiene, asegura Verón, una manifestación material, condición necesaria para poder desarrollar un estudio empírico del proceso de producción de sentido.

Siempre partimos de "paquetes" de materias sensibles investidas de sentido que son productos; con otras palabras, partimos siempre de configuraciones de sentido identificadas sobre un soporte material (texto lingüístico, imagen, sistema de acción cuyo soporte es el cuerpo, etcétera...) que son fragmentos de la semiosis. Cualquiera que fuere el soporte material, lo que llamamos un discurso o un conjunto discursivo no es otra cosa que una configuración espacio-temporal de sentido.

Las condiciones productivas de los discursos sociales tienen que ver, ya sea con las determinaciones que dan cuenta de las restricciones de generación de un discurso o de un tipo de discurso, ya sea con las determinaciones que definen las restricciones de su recepción. Llamamos a las primeras condiciones de producción y, a las segundas, condiciones de reconocimiento. Generados bajo condiciones determinadas, que producen sus efectos bajo condiciones también determinadas, es entre estos dos conjuntos de condiciones que circulan los discursos sociales. (Verón, 1998: 126, 127)

De este modo, se analiza el sentido que circula socialmente. Claro, es una especie de análisis sincrónico de los sentidos socialmente relevantes en un momento dado. Pero de la misma manera en la que Marx asegura que a partir de la anatomía del hombre podemos estudiar a la anatomía del mono (Marx, 1973) para ejemplificar que a partir de un producto se puede dar cuenta de los avatares de su constitución, también Verón asegura que el análisis de una coyuntura significante particular se puede estudiar su recorrido: "La posibilidad de todo análisis del sentido descansa sobre la hipótesis según la cual el sistema productivo deja 


\section{REVCOm \\ REVISTA CIENTIFICA DE LA REDCOM}

REVCOM | ISSN 2451-7836 | Año 4, \#8 | mayo de 2019 | Contribuciones | e009

huellas en los productos y que el primero puede ser (fragmentariamente) reconstruido a partir de una manipulación de los segundos. Dicho de otro modo: analizando productos, apuntamos a procesos." (Verón, 1998: 124)

\section{Discurso y significaciones sociales}

De esta manera, la representación de la realidad no es una cuestión de copia o reflejo, una mera mostración de lo existente, sino que adviene como una totalidad organizada en su misma presentación (re-presentación, volver a presentar), que supone alguna organización de sentido que depende más del polo organizador (cada diario en la prensa gráfica, por ejemplo) que del conjunto de elementos organizados. La realidad, así, puede entenderse como diferentes interpretaciones de lo real. Estas diferentes interpretaciones son maneras de ver la realidad.

Con esto no queremos decir que la realidad se construya solamente a partir de "interpretaciones", ${ }^{3}$ tanto individuales como colectivas, dando así lugar a un sinfín de potenciales "verdades" dependientes de cada una de las miradas, sino que -antes bien- lo que queremos señalar es que esas interpretaciones deben, por decirlo de alguna manera, "apoyarse" sobre un sustrato objetivo que las habilite por un lado (una interpretación es siempre interpretación de algo) y las legitime por el otro; es decir, las interpretaciones de la realidad son un terreno de disputa, de lucha política por lograr la legitimidad de la "mirada" que permita describir al mundo "tal cual es".

Para poner un ejemplo de qué estamos diciendo cuando sostenemos que las interpretaciones de la realidad deben tener algún sustento o sustrato objetivo que las habilite y legitime, nos permitimos tomar un ejemplo utilizado por Chantal Mouffe y Ernesto Laclau en su libro Hegemonía y estrategia socialista:

a. El hecho de que todo objeto se constituya como objeto de discurso no tiene nada que ver con la cuestión acerca de un mundo exterior al pensamiento, ni con la alternativa realismo/idealismo. Un terremoto o la caída de un ladrillo son hechos perfectamente existentes en el sentido de que ocurren aquí y ahora, independientemente de mi voluntad. Pero el hecho de que su especificidad como

3 Por supuesto, lo que sí hacemos explícito de esta manera es nuestro alejamiento respecto de cualquier propuesta esencialista, que busca en las cosas una verdad o una esencia eterna, inmutable e inconmovible a través del tiempo. Al respecto, por citar un ejemplo, véase Hospers, John, Introducción al análisis filosófico. Alianza, Madrid, 1982 (Apartado 6: Verdad). 
REVCOM | ISSN 2451-7836 | Año 4, \#8 | mayo de 2019 | Contribuciones | e009

objetos se construya en términos de "fenómenos naturales" o de "expresión de la ira de Dios" depende de la estructuración de un campo discursivo. Lo que se niega no es la existencia, externa al pensamiento, de dichos objetos, sino la afirmación de que ellos puedan constituirse como objetos al margen de toda condición discursiva de emergencia.

b. En la raíz del prejuicio anterior se encuentra un supuesto que debemos rechazar: el del carácter mental del discurso. Frente a esto, afirmaremos el carácter material de toda estructura discursiva. (Laclau y Mouffe, 2004: 146, 147)

Así, el problema central que organiza la mirada teórica de estas líneas viene definido por lo que Sergio Caletti denomina "la producción social de significaciones (PSS)", ${ }_{4}$ problemática cuyo planteo en profundidad, excede a este trabajo, pero de la que se delinearán sus contornos generales para avanzar en la redefinición que nos proponemos.

Estos procesos de producción social de significaciones se dan en la superficie discursiva, a través del discurso, pero aquí no entendemos discurso como relacionado estrictamente a lo verbal, o como equivalente de enunciación o enunciado, ni como un texto en tanto superficie para ser leída. La noción de discurso se relaciona más con una idea de discurso social que es retomado incesantemente en la inmensa variedad de enunciados concretos y las relaciones que constituyen y establecen entre sí al conformarse sistemas de enunciados. Al borrarse, afirma Caletti, "las huellas al menos más visibles e inmediatas de la enunciación".

En la noción de discursividad social, lo que emerge al primer plano no es el autor sino el carácter social, anónimo, colectivo de las significaciones puestas en juego. Sólo por esta desindividualización, el discurso puede existir como una superficie productiva que plantea a los hablantes (deberíamos poder decir "comunicantes" para no recaer en la verbalidad de los signos) haces de encadenamientos significantes. Sólo por esta desindividualización es en la superficie del discurso en la que se resuelve el campo entero de lo que las cosas presumiblemente son. Esta superficie es móvil y cambiante, en la misma medida en que se encuentra continuamente bombardeada -aunque debiéramos decir enriquecida, vuelta más densa- por enunciaciones que, más allá de la agudeza o rapidez con que lo advirtamos, desplazan en un sentido u otro las significaciones previas, las reformulan, refuerzan o reconfiguran las cadenas posibles,

4 Al respecto, véase En torno de la subjetividad y otros textos (borradores de trabajo para la discusión). Ficha de cátedra de Teoría y Prácticas de la Comunicación III, Facultad de Ciencias Sociales (UBA). Buenos Aires, "Siete tesis sobre comunicación y política", en Diálogos de la comunicación n63, Buenos Aires, FELAFACS, diciembre 2001, entre otros. 


\section{$\checkmark$ REVCOm \\ REVISTA CIENTIFICA DE LA REDCOM}

REVCOM | ISSN 2451-7836 | Año 4, \#8 | mayo de 2019 | Contribuciones | e009

las cadenas típicas, las cadenas preferentes de unos y otros. (...) Nadie es profeta en su tierra porque en su tierra lo que profiere seguramente tiene mucho más que ver con discursos que circulan socialmente y poco con decires extraordinarios. (Caletti, 2001: 47)

Es en esta disputa por el encadenamiento de esos enunciados, y de esas enunciaciones, en donde se produce la significación -y lo social agrega que las intervenciones la inmensa mayoría de las veces no se hacen a título personal, ${ }^{5}$ sino desde un lugar de anonimato pero que no deja de tener carácter de intervención social, al retomar y reproducir -o modificar- las significaciones sociales dominantes. Como dijimos, una de ellas es la hoy cuestionada idea del periodismo como un "reflejo" de la realidad.

La realidad, esa masa material y significante, es construida a partir del encadenamiento de distintas enunciaciones que producen cierta significación específica sobre el mundo, y no otro. Proceso que, como dijimos, es social, en tanto que impersonal y colectivo, y que rescata lo dicho para ser actualizado en el decir. En un sentido estricto, esta postura implica el carácter ideológico de tales enunciados, ya que refieren a la significación y, por lo tanto, a la valoración de esos objetos - del mundo. ${ }^{6}$

Esta concepción que guía nuestro análisis, así, se relaciona con lo que diversos autores conceptualizaron como discurso. ${ }^{7}$ Como señalan Ernesto Laclau y Chantal Mouffe:

Nuestro análisis rechaza la distinción entre prácticas discursivas y no discursivas y afirma: a) que todo objeto se constituye como objeto de discurso, en la medida en que ningún objeto se da al margen de toda superficie discursiva de emergencia; b) que toda distinción entre los que usualmente se denominan aspectos lingüísticos y prácticos (de acción) de una práctica social, o bien son distinciones incorrectas, o bien deben tener lugar como diferenciaciones internas a la producción social de sentido, que se estructura bajo la forma de totalidades discursivas. (Laclau y Mouffe, 2004: 144, 145).

Vale recordar que decir que "todo objeto se constituye como objeto de discurso" no implica negar la materialidad de lo real; antes bien, esa constitución como objeto de discurso

5 Vale aclarar que las cuestiones del sujeto de razón/de conciencia quedan también rechazadas de plano por esta perspectiva.

6 Véase, como ejemplos de lo dicho, el concepto de "signo ideológico" en Voloshinov, Valentin, El marxismo y la filosofía del lenguaje, ediciones Godot, 2009, p. 26 y ss o el de "ideología" en Althusser, Louis, "Marxismo y Humanismo" en La revolución teórica de Marx, Siglo XXI, 2004, p. 191 y ss.

7 Cada uno con sus particularidades, y sus diferencias: Foucault, Derrida, los propios Laclau y Mouffe, Pecheux, por citar algunos ejemplos. 


\section{$\searrow_{\text {REVCOM }}$ \\ REVISTA CIENTIFICA DE LA REDCOM}

REVCOM | ISSN 2451-7836 | Año 4, \#8 | mayo de 2019 | Contribuciones | e009

implica dotar de significación a esa materialidad (el caso más concreto puede ser, para poner un ejemplo burdo, un edificio: no significa lo mismo si es una escuela, una prisión, un hospital o una mansión. Para nosotros, siguiendo a Althusser, toda ideología es material en tanto define prácticas).

Esto plantea que, sobre la materialidad de lo real, la realidad se "construye" a partir de las significaciones que organizan de algún modo esa realidad; es decir, tiene que haber algún orden, tenemos que poder entender (y comprender) lo que significa cada elemento de la realidad. Si algo no tiene sentido, si no significa, no tiene relevancia social.

Un último comentario respecto de la noción de discurso, su función performativa y su carácter social, Eliseo Verón sostiene que fue Charles Peirce quien definió la problemática teórica central de la semiótica: "la de las relaciones entre la producción de sentido, la construcción de lo real y el funcionamiento de la sociedad" (Verón, 1998: 120).

\section{La práctica periodística y la definición de información}

En la primera década del siglo XXI, en nuestro país se puso en foco la discusión sobre cuál es el rol de los medios en la consolidación de la democracia, y de la mano de esos debates fue cuestionada la noción de la "objetividad" periodística, tanto como objetivo profesional como también su carácter de ideal social. Así, dentro de las concepciones de sentido común que se sostienen sobre lo que es el periodismo y la manera de ejercerlo, se incluye, muchas veces, de manera implícita (conciente o inconscientemente) la forma en la que esta actividad específica interviene en la vida social.

En esta línea, vale una breve definición de lo que entenderemos como práctica periodística: una práctica social que tiene como resultado un producto particular, la información, y que sostiene su carácter de social en tanto su valor significante (los órdenes sociales que habilita) permiten concebir a lo social como un todo organizado de una manera específica; es decir, como dotado de sentido. Por ello, esa práctica articulatoria organiza alguna forma de identidad (o significación, aquí vale también), pero también como una configuración de algún contenido ideológico que define la forma en la que actuaremos en el mundo, y en ese marco constituirse como práctica material en el sentido althusseriano.

El propio Althusser definió conceptualmente la "práctica" como una relación activa con lo real. Por ello, nos valdremos también de sus palabras para reflexionar sobre lo que nosotros llamamos la "práctica periodística". 
REVCOM | ISSN 2451-7836 | Año 4, \#8 | mayo de 2019 | Contribuciones | e009

Toda práctica es, pues, social. Y, siendo social, pone en juego tal complejidad de elementos (en el caso de la producción: las materias primas, los agentes de la producción, los instrumentos de la producción, todo ello ajustado a las relaciones sociales de producción) que es imposible pensarla como un simple acto, ni siquiera como una simple actividad. (...) De modo que nos sentimos naturalmente llevados a concebir las prácticas sociales no como actos ni como simples actividades, sino como procesos; vale decir, como un conjunto de elementos materiales, ideológicos, teóricos y humanos (los agentes) suficientemente adaptados unos a otros para que su acción recíproca produzca un resultado que modifique los datos de partida.

Llamaremos entonces "práctica" a un proceso social que pone a agentes en contacto activo con lo real y produce resultados de utilidad social. (...) Para comprender lo que es la práctica, hay que pasar por reconocer la existencia de prácticas sociales distintas y relativamente autónomas. La práctica técnica no es la práctica científica, la práctica filosófica no se confunde con la práctica científica, etcétera. (Althusser, 2015: 102, 103)

Por supuesto, entre esas "prácticas sociales distintas" podemos incluir la "práctica periodística", en tanto produce resultados de utilidad social y no se confunde con las demás prácticas (es decir, tiene su propia especificidad).

Ahora bien: en primer lugar, y como dijimos, el sentido común ubica al periodismo como un "reflejo", una "mediación" entre la noticia (que tendría una existencia autónoma en tanto tal, independiente de su difusión mediática) y los ciudadanos-lectores, suponiendo una especie de transparencia de la actividad del profesional periodista: éste no altera la "noticia", obviamente no la inventa; sólo -a través de su mediación- le da "estado público". De más está aclarar que no es esta visión de la actividad periodística la que sostenemos en este trabajo.

La segunda posibilidad, y que es la que guía nuestro análisis, concibe al periodismo como una práctica que, de una manera muy específica, construye la realidad (social) que se supone que describe. $Y$ la herramienta central de esa construcción es la información, pero entendida como una mercancía en el sentido marxista, en tanto borra los elementos de su constitución. Dicho de otra manera: construye (da forma, in-forma) lo que dice que describe, ocultando en ese movimiento su intervención "organizadora".

Esta comparación se sostiene, a nuestro entender, a partir del análisis que realiza el filósofo esloveno Slavoj Zizek de la frase de Karl Marx "No lo saben, pero lo hacen", el concepto de mercancía que figura en el capítulo sobre "El fetichismo de la mercancía y su secreto" en El Capital, y la lectura que hace Peter Sloterdijk de ese mismo pasaje. 


\section{REVCOm \\ REVISTA CIENTIFICA DE LA REDCOM}

REVCOM | ISSN 2451-7836 | Año 4, \#8 | mayo de 2019 | Contribuciones | e009

Permítasenos utilizar unas líneas para justificar la comparación, apelando a retomar a los autores puestos en relación.

En "El fetichismo...", Marx asegura que, en la vida cotidiana, en el proceso de circulación e intercambio, la producción de la mercancía borra las huellas de su recorrido: desde mera materialidad sensible hasta su emergencia como material "extrasensible", el valor que adquiere en el mercado está determinado por ser producto del trabajo humano. Marx afirmaba que nadie desconocía esto, pero lo que parecía no poder "descubrirse" era el secreto de la mercancía. Ese secreto era su forma mistificada; es decir, la forma-mercancía. La imperiosa necesidad de la apariencia era lo que otros no pudieron ver. Es aquí donde puede realizarse la homología con el concepto de información que trabajamos: podemos decir que ya sabemos que es siempre un sujeto $^{8}$ el que escribe, el que habla, el que marca un "punto de vista"; pero el secreto no está en su forma: está en la necesaria apariencia de "objetividad" que debe revestir toda información.

Por ello, Zizek se hace la misma pregunta, pero a partir de la "crítica ideológica" cuyo germen fuera la frase de Marx, "ellos no lo saben, pero lo hacen". Hoy ya "lo sabemos", ¿esto quiere decir que es el fin de la(s) ideología(s)? (Zizek, 2003; 55-58). El esloveno retoma a Peter Sloterdijk y sus reflexiones sobre el cinismo: a pesar de que conocemos la ilusión nos empeñamos en sostener la máscara. Así, dice, todo elemento se protege de antemano de su crítica ideológica, teniéndola en cuenta desde el principio. Y reformula la frase de Marx: "Lo saben, y aún, así lo hacen". Pero, a pesar de esto, Zizek opta por no abandonar la crítica ideológica, ya que encuentra una falla el planteo del cinismo, porque pasa por alto la cuestión de la objetividad de la creencia, fundamental para él. O como diría Louis Althusser: la materialidad de la ideología, manifestada en actos materiales insertos en prácticas materiales, de carácter objetivo (Althusser, 2005). ${ }^{9} \mathrm{Y}$ por ello resalta que la ilusión, la máscara, la pantalla no está del lado del saber, sino antes bien del lado del hacer: los hombres son fetichistas en la práctica, no en el conocimiento (Zizek: 2003). En la práctica (en el intercambio diría Marx) los hombres actúan como si no supieran -que al equiparar mercancías en el mercado lo que hacen es equiparar sus trabajos humanos abstractos, que el rey es rey porque hay quienes adoptan la posición de súbditos y no porque sea una gracia divina, y,...que la información es objetiva porque "refleja" la realidad.

8 No en carácter individual, sino como representante de una posición ideológica.

9 Es en la línea althusseriana que entendemos el concepto de Ideología (entre otros: cf. Ideología y Aparatos Ideológicos del Estado y "Marxismo y humanismo" en La revolución teorica en Marx). 


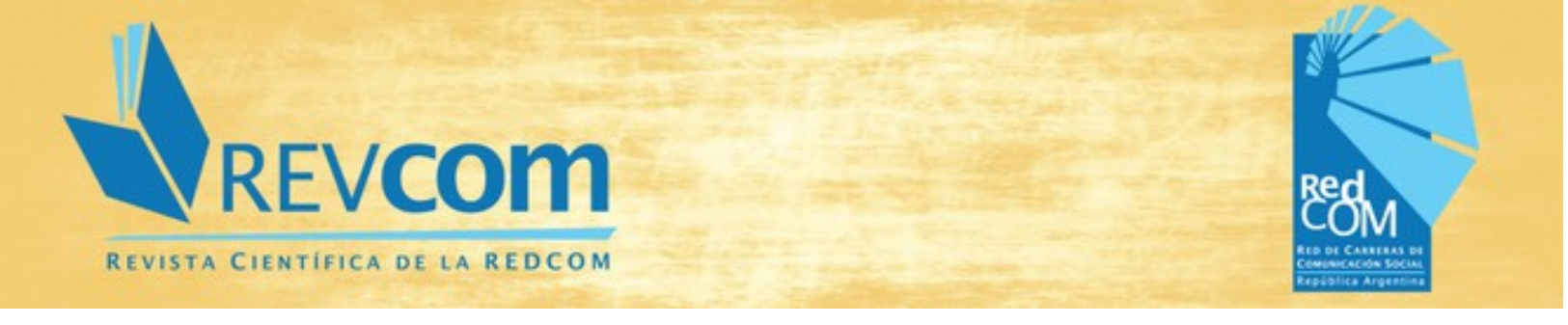

REVCOM | ISSN 2451-7836 | Año 4, \#8 | mayo de 2019 | Contribuciones | e009

Por esto,

nos parece pertinente sostener la posibilidad de intentar una crítica informativa sobre la verdad o la falsedad de la información es no ver el "secreto de la forma": en tanto producción social de significación(es), terreno y herramienta de la lucha ideológica, no puede pensarse en esos términos. Es, más bien, pensar sobre la necesidad de que ese elemento del campo de las significaciones sociales adquiera esa forma. (Ackerman, S. y Morel, Ma. Paula, 2010)

Así, el rodeo que acabamos sirve para poder señalar un mojón conceptual: en tanto define situaciones, también nos brinda el material con el que nosotros definimos (y realizamos) nuestras acciones cotidianas, y la escala de valores con la cual medimos a las cosas, a la "información" que -en el caso del presente trabajo- leemos.

Pero también recordemos que, como se señaló más arriba, esta manera distinta de "evaluar los hechos" nos va a habilitar para actuar de manera diferente en el mundo: no sólo en el sentido más material y vulgar del término "actuar" (como podría ser, por ej.., concurrir -o noa una movilización), sino también que la manera de interpretar los acontecimientos nos va a permitir inscribirlos en procesos de significación diferentes, diversos y hasta en algunos casos opuestos a los que podrían realizarse a partir de miradas desarrolladas desde otras perspectivas. $^{10}$

De esta manera, los medios gráficos se convierten no sólo en superficie de inscripción de las diversas intervenciones de distintos actores sociales, sino que -en nuestra lectura- a través de la forma en la que colaboran en construir una "realidad" (no universal, sino con tensiones, en disputa entre las distintas formas de presentarla, de interpretarla) los mismos medios se convierten en actores sociales que intervienen en esa realidad, $\mathrm{y}$, al presentarla de una $\mathrm{u}$ otra manera, colaboran en la lectura de los distintos sujetos sociales y contribuyen a la definición de diversas conductas; es decir, ayudan a determinar las diferentes maneras en las que los sujetos sociales intervienen en la realidad (a través de proveer "líneas de lectura" de los hechos que llamamos "realidad").

10Podría realizarse un análisis comparativo de las diferentes maneras en las que diversos diarios (Clarín, La Nación y Página/12 alcanzarían para ejemplificar lo aquí dicho) para ver la manera en la que este proceso se lleva a cabo. 
REVCOM | ISSN 2451-7836 | Año 4, \#8 | mayo de 2019 | Contribuciones | e009

\section{Para seguir pensando}

En esta línea de reflexiones, creemos que podemos plantear con legítimo derecho que los medios gráficos, específicamente los periódicos, juegan un doble papel en el problema de la producción social de significaciones, que serían:

- por una parte, y en tanto funcionan como "canales de información" en la estructura social, en ellos se inscriben las intervenciones (las enunciaciones, o las comunicaciones, diría Caletti) de diferentes actores de la vida social y, al aparecer en sus páginas, dejan una marca, una inscripción específica en la superficie discursiva; superficie que puede ser transformada o modificada por esa inscripción;

- pero también los diarios mismos, con esa inscripción y con sus propias "opiniones" (por ej. las columnas de opinión o los editoriales, pero también -y no menos importante- la selección de los temas que ameritan ser "información" publicada, e incluso la elección de quienes tienen voz para decir respecto de ella), participan de esa superficie discursiva dejando su marca ya no como meros "transmisores" (si acaso esto fuera posible), sino con sus propias enunciaciones.

Por eso, trabajar con medios gráficos implica trabajar con una forma particular de PSS, en tanto (siguiendo el "sentido común" respecto del periodismo) borra las huellas de su propia enunciación. Es decir: hay enunciado, pero no hay enunciación. Y a partir de la definición que brindamos del concepto "información", también podemos analizar la manera en la que esos borramientos operan en la PSS. Entonces, es a la luz de estas conceptualizaciones que las tesis presentadas cobran sentido en nuestro texto: surgen del trabajo de definición de las formas y elementos de la práctica periodística que aquí desarrollamos, y son precisamente estas definiciones las que nos habilitan a interrogarnos sobre las cuestiones que abordamos en estas páginas, y tienen que ver con las condiciones de posibilidad de emergencia (recordemos, siempre sociales) de un producto periodístico.

\section{BIBLIOGRAFÍA}

Ackerman, S. y Morel, M.P. (2010), Algunas anotaciones en torno a la producción de información, ponencia presentada en las XIV Jornadas Nacionales de Investigadores en Comunicación. "Investigación y Participación para el Cambio Social", Universidad Nacional de Quilmes, prov. de Buenos Aires. www.redcomunicacion.org/jornadas/jprogramadefinitivo.pdf

Althusser, Louis (2005), Ideología y aparatos ideológicos del Estado/Freud y Lacan. Nueva Visión, Buenos Aires. 
REVCOM | ISSN 2451-7836 | Año 4, \#8 | mayo de 2019 | Contribuciones | e009

Althusser, Louis (2015), Iniciación a la filosofía para los no filósofos. Paidós, Buenos Aires.

Caletti, Sergio (2001), En torno de la subjetividad y otros textos (borradores de trabajo para la discusión).

Ficha de cátedra de Teoría y Prácticas de la Comunicación III, Facultad de Ciencias Sociales (UBA). Buenos Aires.

Laclau, E. y Mouffe, Ch. (2004), Hegemonía y estrategia socialista. Fondo de Cultura Económica, Buenos Aires.

Marx, Karl (1973), Introducción general a la crítica de la economía política/1857, Buenos Aires, Cuadernos de Pasado y Presente.

Verón, Eliseo (1998), La semiosis social. Editorial Gedisa, Buenos Aires.

Zizek, Slavoj (2003), El sublime objeto de la ideología. Siglo XXI Editores, Buenos Aires. 